\title{
Cancer Antigen 125 and Nephrotic Syndrome
}

\author{
Edwin Rolando Castillo Velarde
}

\begin{abstract}
Background: Cancer antigen 125 (CA-125) serves as a nonspecific test for the diagnosis of several pathologic conditions involving a compromised mesothelium resulting from inflammatory processes. This investigation reports the association of CA-125 with severe nephrotic syndrome caused by primary glomerulopathy, which often coexists with inflammation.
\end{abstract}

Methods: CA-125 levels, clinical data and isolated ultrafiltration therapy were assessed with severe nephrotic syndrome. Nineteen patients were recruited with nephrotic syndrome and primary glomerulopathy. Of these, seven patients had criteria for severe nephrotic syndrome which was defined as including all three of the following criteria: 1) proteinuria $\geq 8 \mathrm{~g} / 24 \mathrm{~h} ; 2$ ) the presence of anasarca; and 3) creatinine $\geq 1.2 \mathrm{mg} / \mathrm{dL}$. The nonparametric Spearman Rho and Kruskal-Wallis tests were used to assess these correlations.

Results: There was an increase in CA-125 levels in $85 \%$ of the patients with nephrotic syndrome. The patients defined as having severe nephrotic syndrome showed a median CA-125 value of $1,501 \mathrm{U} / \mathrm{mL}$ (P $<0.001$ ), with levels up to 90 -fold greater than normal during the initial assessment. CA-125 $\geq 700 \mathrm{U} / \mathrm{mL}$ was associated with $100 \%$ sensitivity and $91 \%$ specificity for severe nephrotic syndrome $(\mathrm{P}<0.001)$.

Conclusions: CA-125 test is associated quantitatively with the severity of nephrotic syndrome.

Keywords: CA-125; Nephrotic syndrome; Isolated ultrafiltration therapy

\section{Introduction}

Cancer antigen $125(\mathrm{CA}-125)$ is a glycoprotein of $200 \mathrm{kDa}$ (normal value $\leq 35 \mathrm{U} / \mathrm{mL}$ ) that is normally expressed in coelomic epithelium during fetal development, which is a tissue that later lines the corporal cavities [1]. CA-125 has been used as a marker in non-mucinous epithelial ovarian cancer and to

Manuscript submitted December 13, 2018, accepted December 26, 2018

Division of Nephrology, Department of Medicine, Guillermo Almenara Hospital, Av. Grau 800, Lima; Ricardo Palma University, Santiago de Surco, Peru. Email: edwin.castillo@urp.edu.pe

doi: https://doi.org/10.14740/wjnu385 monitor response to treatment. However, elevated CA-125 has also been observed in other conditions [1-9].

An increase in CA-125 levels is associated with ascites [10, 11]; however, there is no correlation between distention of the peritoneal cavity and the elevation of CA-125, for example in patients with continuous ambulatory peritoneal dialysis, and thus continuous infusion in the peritoneal cavity [7, 12]. Thus, an increase in the CA-125 levels is thought to be associated with inflammatory processesand and may be mediated by proinflammatory cytokines such as IL-1 $\beta$, IL-6, and IL-8, which are produced by mesothelial cells [13-15]. Glomerulopathy in nephrotic syndrome has important inflammatory mechanisms and CA-125 has been reported associated [11], but not with severity.

\section{Materials and Methods}

The data were extracted from inpatients of the Nephrology Service of the Guillermo Almenara Hospital in Peru, from August 2007 to February 2009. A total of 19 patients were recruited. The inclusion criteria were as follows: nephrotic syndrome, ages between 16 and 85 years, and primary glomerulopathy by renal biopsy. The exclusion criteria were as follows: carcinoma of any etiology, utero-adnexal pathology, pregnancy, cirrhosis, portal hypertension, pulmonary and extrapulmonary tuberculosis, decompensated heart failure, and HIV. The severe nephrotic syndrome was defined by the following three criteria: 1) nephrotic range proteinuria $\geq 8 \mathrm{~g} / 24 \mathrm{~h} ; 2$ ) the presence of anasarca, including generalized edema and cavities; and 3) creatinine value $\geq 1.2 \mathrm{mg} / \mathrm{dL}$.

At admission, all the included patients were assessed for these variables: ascites, sex, urine volume, edema, serum CA125 , albumin, proteinuria/ $24 \mathrm{~h}$, triglycerides, cholesterol, creatinine, and urea. All patients with CA-125 $\geq 35 \mathrm{U} / \mathrm{mL}$ were followed with regular monthly checkups (Elecsys CA125 kit, Roche). This monitoring was discontinued once their CA-125 levels returned to normal. The presence of ascites was assessed by ultrasound or tomographic imaging parameters. We assessed the relationship between CA-125, clinical data, nephrotic syndrome, severe nephrotic syndrome and isolated ultrafiltration therapy. Statistical analysis used the Spearman Rho test and Kruskal-Wallis test. Informed consent was obtained from all individual participants included in the study.

\section{Results}

In total, $88 \%$ of the population was between 40 and 69 years old. 
Table 1. Clinical Parameters, Histopathology, and Laboratory Variables (Media) in Nephrotic Syndrome and CA-125

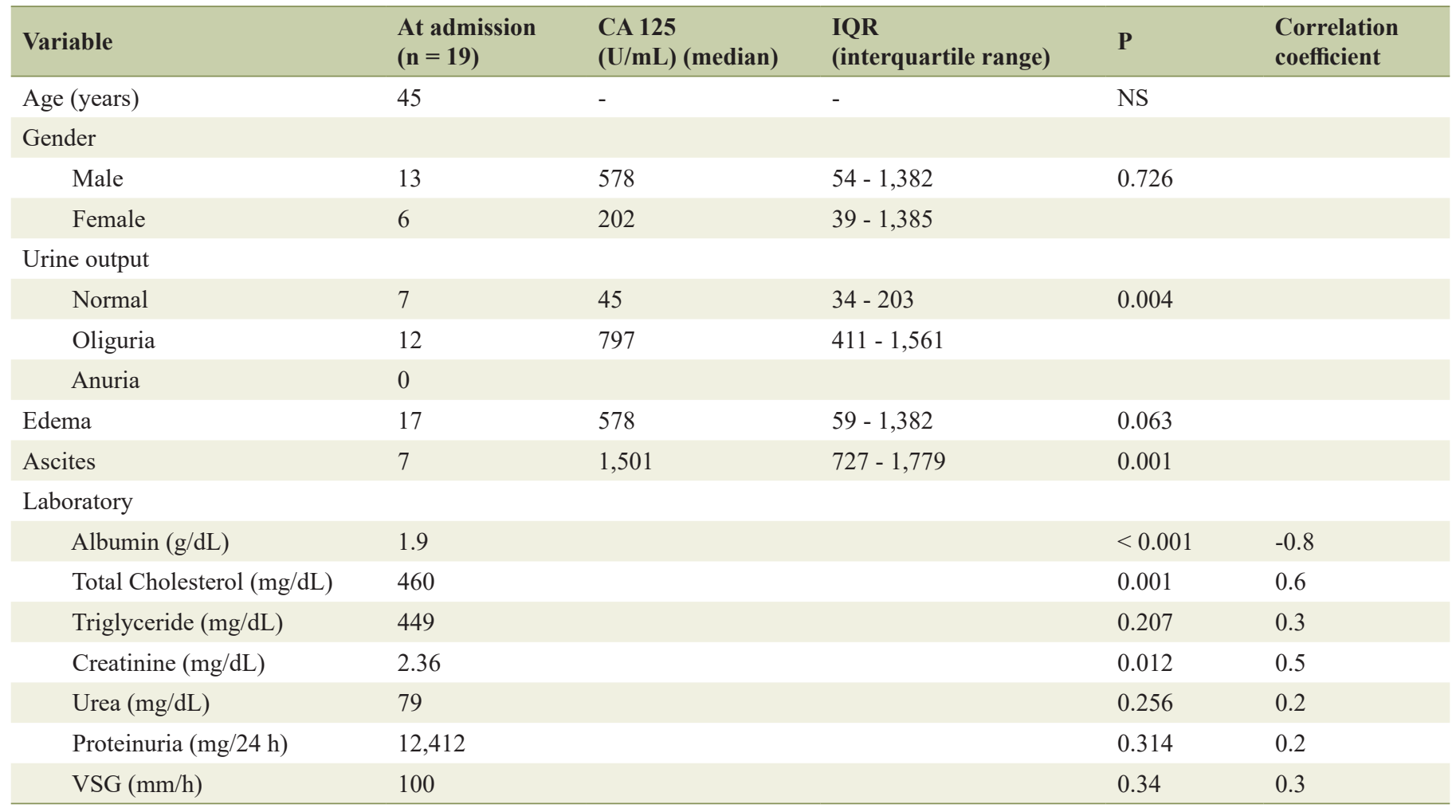

The most frequently observed form of glomerulopathy was focal segmental glomerulosclerosis, which was associated with a median CA-125 value of $719 \mathrm{U} / \mathrm{mL}(\mathrm{P}=0.052)$. Of the 19 patients included, 15 (84\%) had elevated levels of CA-125. At admission, there was a correlation between CA-125 level and ascites $(\mathrm{P}=0.001)$, with a median of $1,500 \mathrm{U} / \mathrm{mL}$. The level of plasma albumin showed a significant negative correlation with CA-125 $(\mathrm{P} \leq 0.001)$ at admission and at follow-up (Table 1). The presence of proteinuria was not significant at admission or during follow-up associated to CA-125 (correlation of 0.2$)(\mathrm{P}=0.05)$.

Of the 19 patients with nephrotic syndrome, seven patients had severe criteria with a median CA-125 level of 1,501 U/ $\mathrm{mL}$ (interquartile range (IQR): 727 - 1,779). The remaining patients had an average CA-125 level of $59 \mathrm{U} / \mathrm{mL}$ (IQR: 35 - 329). Of the seven patients showing severity, five had the focal segmental glomerulosclerosis form and two had the membranous form. The correlation between severity and CA-125 was highly significant $(\mathrm{P}<0.001)$. CA-125 levels of $700 \mathrm{U} /$ $\mathrm{mL}$ predicted severe nephrotic syndrome with a sensitivity of $100 \%$ and a specificity of $91 \%$. The highest value of CA-125 observed in association with nephrotic syndrome was 3,121 U/ $\mathrm{mL}$, which is 90 times the normal value.

A CA-125 level of $700 \mathrm{U} / \mathrm{mL}$ showed a positive predictive value of $87 \%$ and a negative predictive value of $100 \%$ for severe nephrotic syndrome. In patients who underwent isolated ultrafiltration therapy, there was a high correlation between a CA-125 value over $700 \mathrm{U} / \mathrm{mL}$ and indication for this therapy at the time of admission $(\mathrm{P}<0.001)$. In total, $85 \%$ of the patients with severe nephrotic syndrome underwent isolated ultrafiltra- tion therapy.

In the follow-up, the observation period was extended to 10 months, during which time a continuous decrease in the value of CA-125 was observed (Fig. 1).

\section{Discussion}

Most patients with nephrotic syndrome had elevated levels of CA-125. There was a correlation between the level of CA-125 and ascites; however, many patients with nephrotic syndrome have ascites, but not all has an exponential increase of CA-125, so this peak probably is correlated with inflammatory mechanism by the following reasons: 1) In patients with continuous ambulatory peritoneal dialysis, there is no correlation between distention of the peritoneal cavity and the elevation of CA-125 [13]; 2) The levels of CA-125 decreased with time by lower mesothelial turn-over and the absence of pro-inflammatory cytokines [15]. An increase in the CA-125 levels is thought to be associated with inflammatory processes, such as pelvic disease or endometriosis, and may be mediated by pro-inflammatory cytokines produced by mesothelial cells [13-15]. The primary glomerulopathy has relevant inflammatory mechanisms and is accord to clinical severity. In conclusion, this marker is associated quantitatively with the inflammatory process of glomerulopathy with severe nephrotic syndrome. In the clinical practice, there are unspecific tests to many diseases with a predictive level like $\mathrm{C}$-reactive protein, but in this case, there is a mesothelial inflammation mechanism. 


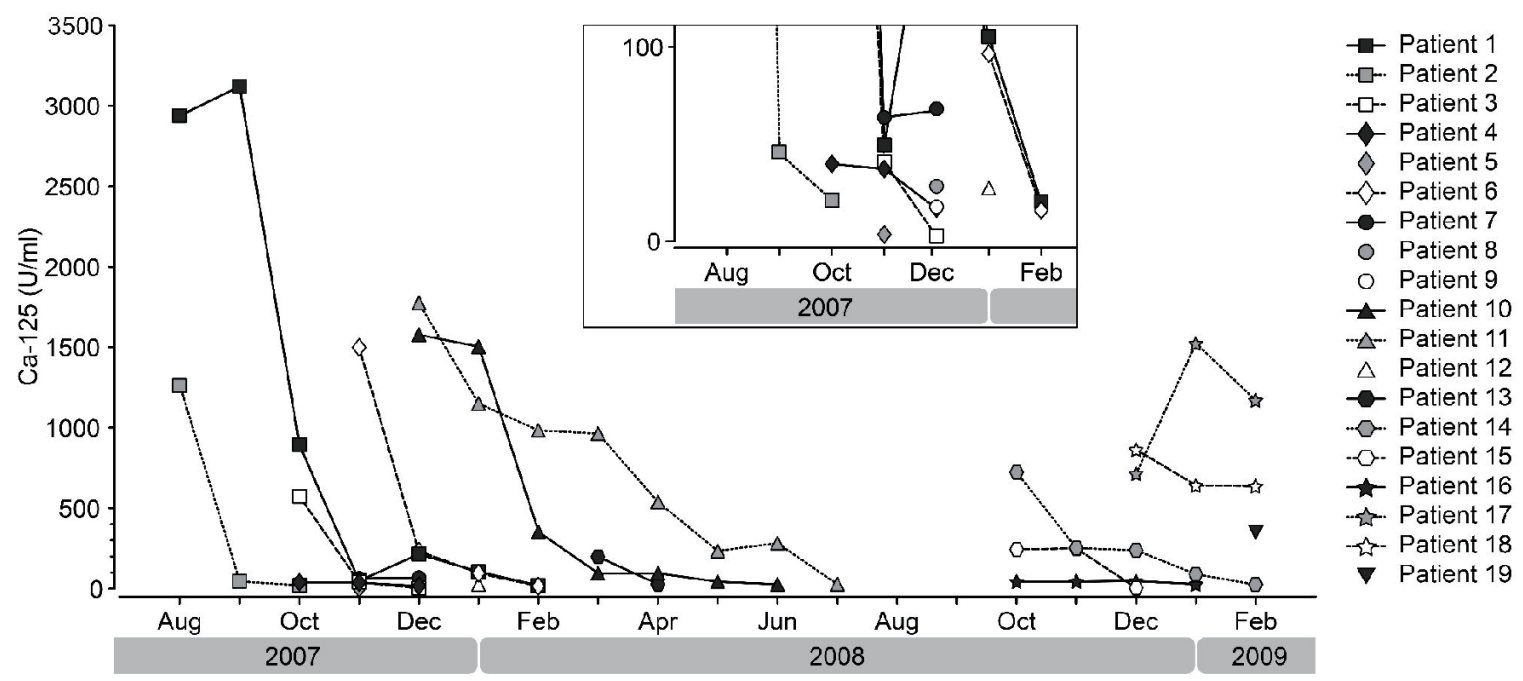

Figure 1. Follow-up of patients with nephrotic syndrome and a level of CA-125 $\geq 35 \mathrm{U} / \mathrm{mL}$ at admission and during the period of study. The level was checked once a month, which was discontinued once a normal value of CA-125 $(\leq 35 \mathrm{U} / \mathrm{mL})$ was reached.

None of the patients who were indicated for isolated ultrafiltration therapy had CA-125 levels $<700 \mathrm{U} / \mathrm{mL}$, so their association with severity is clear; however, it is necessary to increase the number of patients in future reports.

\section{Acknowledgments}

The author thanks Dr. Paredes Giraldo A. of the Nephrology Department, Dr. Alvizuri Pastor S. of the Inmunodiagnostic Laboratory at Hospital Almenara, Lima, Peru, and Dr. GrinyoJosep M. of the Hospital Universitari de Bellvitge, Barcelona, Spain, for their assistance.

\section{Conflict of Interest}

None.

\section{References}

1. Epiney M, Bertossa C, Weil A, Campana A, Bischof P. CA125 production by the peritoneum: in-vitro and invivo studies. Hum Reprod. 2000;15(6):1261-1265.

2. Miralles C, Orea M, Espana P, Provencio M, Sanchez A, Cantos B, Cubedo R, et al. Cancer antigen 125 associated with multiple benign and malignant pathologies. Ann Surg Oncol. 2003;10(2):150-154.

3. Sevinc A, Camci C, Turk HM, Buyukberber S. How to interpret serum CA 125 levels in patients with serosal involvement? A clinical dilemma. Oncology. 2003;65(1):16.

4. Kemer T, Ormen M, Kuralay F, Pehlivan M, Unsal B, Tankurt E. Diagnostic usefulness of carbohydrate antigen-125 in cancerous and noncancerous peritoneal effusions. Tohoku J Exp Med. 2005;205(1):11-18.
5. Yilmaz A, Ece F, Bayramgurler B, Akkaya E, Baran R. The value of $\mathrm{Ca} 125$ in the evaluation of tuberculosis activity. Respir Med. 2001;95(8):666-669.

6. Nagele H, Bahlo M, Klapdor R, Schaeperkoetter D, Rodiger W. CA 125 and its relation to cardiac function. Am Heart J. 1999;137(6):1044-1049.

7. Xiao WB, Liu YL. Elevation of serum and ascites cancer antigen 125 levels in patients with liver cirrhosis. J Gastroenterol Hepatol. 2003;18(11):1315-1316.

8. Ara J, Pascual J, Moises J, et al. Nefropatia membranosa con niveles sericos elevados de Ca125. Nefrologia. 1996;16(6):562-564.

9. Topley N, Michael D, Bowen T. CA125: holy grail or a poisoned chalice. Nephron Clin Pract. 2005;100(2):c5254.

10. Sevinc A, Buyukberber S, Sari R, Turk HM, Ates M. Elevated serum CA-125 levels in patients with nephrotic syndrome-induced ascites. Anticancer Res. 2000;20(2B):1201-1203.

11. Peng T, Guo L, Xia Q, Yang X. Clinical significance of serum CA125 in nephrotic syndrome. Clin Lab. 2012;58(12):113-115.

12. Zeimet AG, Marth C, Offner FA, Obrist P, Uhl-Steidl M, Feichtinger H, Stadlmann S, et al. Human peritoneal mesothelial cells are more potent than ovarian cancer cells in producing tumor marker CA-125. Gynecol Oncol. 1996;62(3):384-389.

13. Zeillemaker AM, Verbrugh HA, Hoynck van Papendrecht AA, Leguit P. CA 125 secretion by peritoneal mesothelial cells. J Clin Pathol. 1994;47(3):263-265.

14. Yao V, Platell C, Hall JC. Peritoneal mesothelial cells produce inflammatory related cytokines. ANZ J Surg. 2004;74(11):997-1002.

15. Rodrigues A, Martins M, Santos M, et al. Evaluation of effluent markers cancer antigen 125, VEGF, IL-6: Relationship with peritoneal transport. Advances in Peritoneal Dialysis. 2004;20:8-12. 